\title{
Meio Ambiente nas Aulas de Ciências: Análise de uma Prática Pedagógica sobre Elementos e Compostos Minerais a partir da Pintura Rupestre
}

\author{
Environment in Science Classes: Analysis of a Pedagogical Practice on Mineral Elements \\ and Compounds from Rock Painting
}

Medio ambiente en clases de ciencias: análisis de una práctica pedagógica sobre elementos minerales y compuestos de la pintura rupestre

\author{
Clara Sena Mata Oliveira \\ Licencianda em Ciências Biológicas, UFLA, Brasil \\ clarabela99@outlook.com \\ Julia Amorim Monteiro \\ Licencianda em Ciências Biológicas, UFLA, Brasil \\ juliaamonteiro9@gmail.com \\ Paulo Antônio de Oliveira Temoteo \\ Mestrando em Educação para Ciência, FC - Unesp - Bauru, Brasil \\ paulo.temoteo@unesp.br \\ Antonio Fernandes Nascimento Junior \\ Professor Doutor, UFLA, Brasil \\ toni_nascimento@yahoo.com.br
}




\title{
Revista Científica ANAP Brasil
}

\author{
ISSN 1984-3240 - Volume 13, número 31, 2020
}

\section{RESUMO}

Os minerais estão presentes no cotidiano de todas as pessoas de diferentes maneiras e pensando que estes são compostos naturais, compreender mais sobre eles possibilita um olhar mais crítico para a natureza. Nesse sentido, esse trabalho tem como objetivo analisar uma prática pedagógica que teve como intuito construir conceitos acerca do tema Elementos e Compostos dos Minerais. A prática emergiu da disciplina Metodologia do Ensino de Ciências, ofertada pelo curso de licenciatura em Ciências Biológicas da Universidade Federal de Lavras. Ao final da prática, foi pedido aos participantes que apontassem os pontos positivos e os pontos a serem melhorados da mesma. Essas falas foram analisadas no âmbito da pesquisa qualitativa, mais especificamente pela análise por categorias, que é derivada da Análise de Conteúdo. Após a análise foi possível constituir três categorias: "Recursos pedagógicos", "Desenho como forma de incentivar a criatividade" e "Domínio do conteúdo por parte da professora". Foi possível perceber a relevância dos recursos pedagógicos, pois foram capazes de instigar a curiosidade dos estudantes. Ainda, a utilização da prática de desenhar foi fundamental para instigar a criatividade dos estudantes, visto que os instigou a participar da aula. Ademais, foi possível perceber a importância do domínio do conteúdo pela professora, visto que é o arcabouço teórico-prático, o qual envolve, dentre outros, saberes científicos e pedagógicos, que possibilita a formação de cidadãos críticos e reflexivos.

PALAVRAS-CHAVE: Metodologia Alternativa. Elementos e Compostos dos Minerais. Formação Inicial de Professores.

\begin{abstract}
Minerals are present in everyone's daily life in different ways and since these are natural compounds, understanding more about them allows a more critical look at nature. In this sense, this paper aims to analyze a pedagogical practice that aimed to build concepts about the theme Elements and Compounds of Minerals. The practice emerged from the Science Teaching Methodology discipline, offered by the Biological Sciences degree course at the Federal University of Lavras. At the end of the practice, participants were asked to point out the positive points and the points to be improved from it. These statements were analyzed in the scope of qualitative research, more specifically by categories analysis, which is derived from Content Analysis. After the analysis, it was possible to establish three categories: "Pedagogical resources", "Drawing as a way to encourage creativity" and "Mastery of the content by the teacher". It was possible to perceive the relevance of pedagogical resources, as they were able to instill the students' curiosity. Still, the use of the practice of drawing was fundamental to instigate students' creativity, as it instigated them to participate in the class. In addition, it was possible to perceive the importance of mastery of content by the teacher, since it is the theoretical-practical framework, which involves, among others, scientific and pedagogical knowledge, which enables the formation of critical and reflective citizens.
\end{abstract}

KEYWORDS: Alternative Metodology. Mineral Elements and Compounds. Initial Teacher Training.

\section{RESUMEN}

Los minerales están presentes en la vida diaria de todos de diferentes maneras y al pensar que estos son compuestos naturales, comprender más sobre ellos permite una visión más crítica de la naturaleza. En este sentido, este trabajo tiene como objetivo analizar una práctica pedagógica que tienhe como objetivo construir conceptos sobre el tema Elementos y compuestos de minerales. La práctica surgió de la disciplina Metodología de la Enseñanza de las Ciencias, ofrecida por el curso de Ciencias Biológicas en la Universidad Federal de Lavras. Al final de la práctica, les pidió a los los participantes que señalaran los puntos positivos y los puntos a mejorar. Estas declaraciones declaraciones fueron analizados en el ámbito de la investigación cualitativa, más específicamente por análisis por categorías, que se deriva del análisis de contenido. Después del análisis, fue posible crear tres categorías: "Recursos pedagógicos", "Dibujo como una forma de fomentar la creatividad" y "Dominio del contenido por parte del profesor". Era posible percibir la relevancia de los recursos pedagógicos, ya que podían inculcar la curiosidad de los estudiantes. Aún así, el uso de la práctica del dibujo fue fundamental para estimular la creatividad de los estudiantes, ya que los instigó a participar en la clase. Además, fue posible percibir la importancia del dominio del contenido por parte del profesor, ya que es el marco teórico-práctico, que implica, entre otros, el conocimiento científico y pedagógico, que permite la formación de ciudadanos críticos y reflexivos.

PALABRAS CLAVE: Metodología Alternativa. Elementos minerales y compuestos. Formación inicial del professorado. 


\section{INTRODUÇÃO}

A relação do homem com a natureza se baseia ao longo da história moderna em uma relação de exploração do meio ambiente para atender às suas necessidades. Percebendo que essa relação se dá numa esfera social, e a forma como a sociedade se organiza é que mostra como vão se dar as relações, ao extrapolar nosso olhar para o todo, ou seja, voltar nossa atenção para o sistema ao qual estamos inseridos (capitalista), existem além de muitas questões, um processo de apropriação e exploração dos recursos naturais - onde as grandes empresas se estabelecem, modificam e exploram até seu esgotamento (SOUZA et al., 2019). Diante desse contexto atual, constatamos uma relação direta entre desenvolvimento econômico, qualidade de vida e consumo de bens materiais, sendo importante ressaltar que os recursos existentes devem ser explorados em benefício da sociedade e não para um pequeno grupo capitalista (SANTOS, 2009). Nesse cenário, surge a necessidade de educar o ser humano para uma consciência ambiental que vai além de entender sobre conservação dos recursos, mas sim que se debruce sobre quais são esses recursos, como eles foram formados, onde são encontrados na natureza, ou seja, para que o sujeito seja alfabetizado cientificamente e que assim seja capaz de participar da tomada de decisões (CACHAPUZ et al., 2005). Tal participação, de acordo com os mesmos autores, deve tornar possível a compreensão dos problemas e das opções de resoluções, levando a aprendizagem das ciências uma aventura potencializadora do espírito crítico.

Essas colocações estão de acordo com os objetivos dos Parâmetros Curriculares Nacionais (PCN) para o ensino de Ciências Naturais no Ensino fundamental, que diz respeito a uma formação dos sujeitos voltada para a compreensão do mundo, de forma que este atue como cidadão e para isto utilize conhecimentos adquiridos através do estudo da ciência e tecnologia (BRASIL, 1998). Além disso, os PCN preveem que o estudante "compreenda a natureza como um todo dinâmico e o ser humano, em sociedade, como agente de transformações do mundo em que vive em relação essencial com os demais seres vivos e outros componentes do ambiente" (BRASIL, 1998, p. 65).

Para que os objetivos dos PCN sejam atingidos, são selecionados conteúdos que sejam relevantes do ponto de vista social para que os estudantes percebam as relações que existem entre os conteúdos que aprendem com a realidade em que estão inseridos e mais ainda, percebem que sociedade, natureza e indivíduos não estão dissociados. De acordo com Quirino et al. (2018), esses conteúdos devem abordar fatos, conceitos, procedimentos, atitudes e valores que são promovidos de acordo com a necessidade de aprendizagem dos alunos para que este possa avançar em seus conhecimentos.

Pensando nessas questões e entendendo que, para que o processo de ensino e aprendizagem seja de fato eficiente em cumprir seu papel, a disciplina de Metodologia do Ensino de Ciências ofertada para o curso de licenciatura em Ciências Biológicas da Universidade Federal de Lavras (UFLA) traz reflexões necessárias para a formação inicial de professores e possibilita uma aproximação entre os conteúdos específicos das ciências aos conteúdos pedagógicos do curso, pois propõe aos estudantes a elaboração de metodologias não expositivas para o ensino do tema das Ciências, pois entende que o ensino tradicional é deficiente, já que desconsidera o 


\section{Revista Científica ANAP Brasil}

ISSN 1984-3240 - Volume 13, número 31, 2020

conhecimento prévio dos estudantes e os entende como caixas vazias prontas a serem preenchidas (MONTEIRO et al., 2018).

As metodologias de ensino alternativas - ou ativas - passam a ser uma alternativa ao ensino tradicional ao passo que essa maneira de trabalhar leva em conta o fato de que os estudantes não podem ser colocados como seres passivos na construção do conhecimento, uma vez que é mais interessante que o ensino não se baseie em memorização de vocábulos, pois esta memorização aumenta a distância entre o aluno e o entendimento do funcionamento do mundo e da sociedade que o cerca. Partindo dessa concepção, quando o professor desenvolve métodos que vão além de giz, quadro, livros e provas, a aula passa a ter outro viés, que vai transcendendo o ato de decorar conceitos para a aprovação em um exame, permitindo que o professor assuma sua função como norteador. Tardif, Lessard e Lahaye (1991) sustentam essa ideia ao apontarem que a relação do educador com o saber não se limita a uma função de transmissão de conhecimentos já constituídos, uma vez que o docente deve assumir um papel norteador, fornecendo ferramentas para que os estudantes compreendam o mundo em que estão inseridos, a fim de atuarem como seres ativos na sociedade.

Pensando nessas questões, um dos temas trabalhados na disciplina citada acima, foi Elementos e Compostos Minerais. Para Hagy (2009) os minerais são compostos inorgânicos que ocorrem na natureza, encontrados na crosta terrestre e apresentam composição química definida e características físicas específicas. Podem ser identificados por sua cor, brilho, traço, fratura, textura, dureza, densidade, peso e clivagem. É interessante ressaltar que as rochas e minerais não são encontrados exclusivamente em ambientes naturais, mas estão presentes no cotidiano de todas as pessoas.

O fato de vivermos em um cenário cercado de tecnologias avançadas articulado com a alienação existente no processo de fabricação das coisas, faz com que haja um distanciamento das pessoas do verdadeiro processo que aquele utensílio sofreu para ter sua forma modificada. (SANTOS et al., 2012). Para Correia (2014), a população em geral se beneficia da utilização de rochas, minerais, e dos seus derivados sem saber de onde vêm o produto manuseado na sua vida diária. Desse modo, o conceito sobre os elementos e compostos que formam os minerais é fundamental para o entendimento da sua ampla utilização e sua importância.

Para Santos et al. (2012), as rochas e minerais são de grande relevância para a humanidade, e estão presentes em nosso cotidiano. Nesse contexto, devemos compreender e ter conhecimento sobre a origem e utilização de cada um desses elementos, considerando suas propriedades e características. No nosso dia-a-dia podemos encontrar minerais ou rochas fazendo parte da composição de vários objetos.

Ensinar esses temas, portanto, é de extrema importância para a formação de cidadãos que sejam capazes de compreender a realidade, pois como apontam Santos e Volkmer (2009) há uma relação direta entre desenvolvimento econômico, qualidade de vida e consumo de bens minerais, sendo importante ressaltar que os recursos minerais existentes devem ser explorados em benefício da sociedade e não apenas de uma classe. É se apropriando dessas discussões, leis, teorias e conceitos que regem a natureza e a sociedade, que os estudantes conseguirão se tornar sujeitos críticos, aptos a compreender o mundo em sua totalidade (MONTEIRO et. al, 2018).

Diante dessas discussões, o professor de ciências pode trabalhar conceitos biológicos, físicos, químicos e matemáticos, criando um ambiente de construção de múltiplos saberes que se 
relacionam, se modificam e se movimentam, os quais, em conjunto, podem instigar a reflexões e a interpretações dos alunos em relação à realidade em que se inserem (SILVA, MONTEIRO, NASCIMENTO JÚNIOR, 2019). Fundamentando-se dessas ideias, compreender os processos que permeiam e constituem o mundo é, na mesma instância, propiciar a integração dos estudantes ao ambiente a que pertencem de maneira crítica. Além disso, Costa e Loureiro (2015) discutem que a Educação Ambiental pode ter um olhar interdisciplinar como alternativa para permear o debate pedagógico, observando suas sustentações e limitações, pois é importante que haja uma análise crítica dos fundamentos e dos efeitos na educação que se produz e se reproduz em uma sociedade estruturada sob classes econômicas.

Para a construção dos conceitos por trás do tema Elementos e Compostos dos Minerais, partiuse de tintas feitas com pó de mineral para que os discentes pudessem enxergar as características de cores, partindo de estudos das manifestações artísticas dos primeiros hominídeos que desenvolveram técnicas para pintar, gravar e esculpir na rocha através dos minerais (JUSTAMAND et al., 2017). Por conseguinte, utilizou-se o recurso de desenho para ampliar tal percepção da característica e por fim utilizou-se uma música. Tanto os desenhos quanto a música se configuram como arte, ou seja, são produções essencialmente humanas. Ao se apropriar dessas expressões, os sujeitos experimentam outras emoções, novas experiências (ARANHA; MARTINS, 1986). Levar a arte para dentro da sala de aula, portanto, é potencializar a educação dos jovens pois, de acordo com Gramsci "a arte educa enquanto arte, e não enquanto arte educativa" (apud KONDER, 2013, p. 107)

O desenho é algo presente na infância de muitas crianças, nos permite analisar o desenvolvimento do processo de aprendizagem e inserção no meio social. Laburú et. al (2009) que analisaram a uma experiência com desenhos no ensino, afirma que esse recurso é uma possibilidade informal de reconhecer os objetos, conteúdos e fenômenos, de uma forma qualitativa que estão sendo aprendidos. Ainda, os autores afirmam que a rotina do exercício do desenho faz parte do crescimento e permite analisar a aprendizagem empregada no mesmo, como também as significações do estudante ao ter o recurso como ferramenta pedagógica.

No que diz respeito a música, essa pode ser entendida como um ótimo recurso a ser utilizado dentro das salas de aula, uma vez que é de fácil acesso e possui grande potencial, uma vez que possibilita ao estudante ter contato com um dos tipos de artes e, ainda, é uma estratégia que pode apresentar um leque de possibilidades para se desenvolver aulas dinâmicas e interativas (SOUZA; VALLIN; NASCIMENTO JUNIOR, 2018). A música também se destaca como recurso pois pode ser empregada em todas as disciplinas, desde que haja um diálogo entre o conteúdo científico e o conteúdo da música, podendo, portanto contribuir para a popularização da ciência, se transformando em um importante recurso pedagógico (OLIVEIRA et al., 2008).

Diante desse contexto, este trabalho tem o objetivo de analisar uma prática pedagógica elaborada no âmbito da disciplina Metodologia do Ensino de Ciências que teve como intuito construir conceitos acerca do tema Elementos e Compostos dos Minerais em um contexto de formação inicial de professores. 


\section{DESENVOLVIMENTO DO TRABALHO}

Abaixo será descrito o contexto no qual a aula aqui analisada surgiu bem como a descrição da mesma.

\subsection{Proposta da disciplina}

A disciplina de Metodologia do Ensino de Ciências é ofertada para o curso de Licenciatura em Ciências Biológicas da Universidade Federal de Lavras e tem como objetivo auxiliar na formação da identidade docente dos licenciandos, através de reflexões a partir do contexto em que o sistema educacional está inserido, permitindo que se construa um olhar crítico acerca da realidade que o processo educativo se encontra (PAULA et al., 2018). Nessa disciplina, os licenciandos são instigados a desenvolverem metodologias alternativas de ensino para temas das Ciências, tomando como base os PCN (BRASIL, 1998).

A aula aqui analisada teve duração de trinta minutos e teve como objetivo construir os conceitos acerca dos elementos e compostos dos minerais.

\subsection{Percurso didático-pedagógico}

A aula aqui analisada teve duração de cinquenta minutos e foi ministrada aos discentes matriculados na disciplina de Metodologia do Ensino de Ciências da grade de licenciatura em Ciências Biológicas da Universidade Federal de Lavras - MG. A aula foi dividida em quatro momentos: problematização a partir de uma caixa mistério, pinturas utilizando tintas preparadas com resíduos dos minerais, problematização a partir dos desenhos e avaliação da aula partindo da música "Ouro Escravo", de 1969 do grupo "Em cima da hora".

No primeiro momento da atividade, foi apresentada uma caixa denominada "Caixa Mistério" (IMAGEM 1) preparada pela própria professora e, a partir dela, foram apontadas dicas do possível objeto escondido dentro da caixa, sendo elas "o objeto contém muitos anos de história", "contesta o estreito de Bering" e "é composto por minerais".

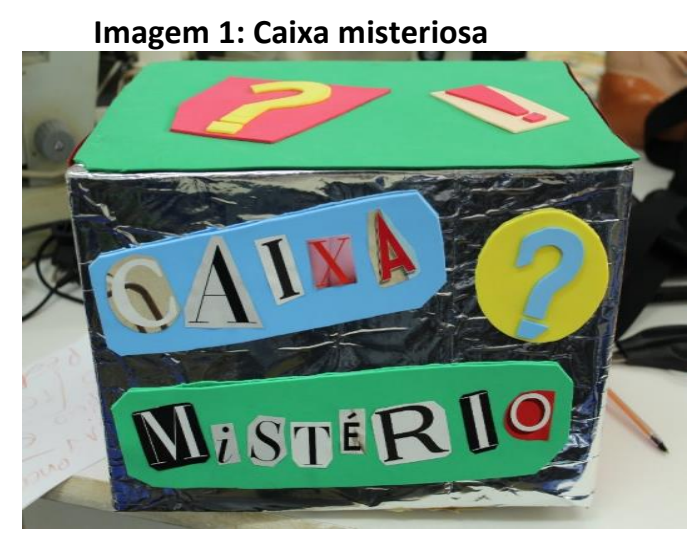

Fonte: AUTORES, 2018

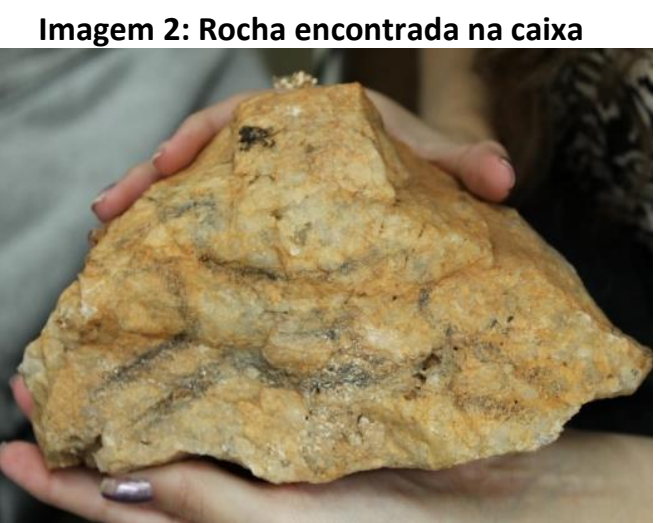

Fonte: AUTORES, 2018

Isso fez com que os estudantes fossem instigados a participar da aula e, após a abertura da caixa, os alunos acertaram qual era o objeto: uma rocha (IMAGEM 2). Neste momento, a professora 


\section{Revista Científica ANAP Brasil}

ISSN 1984-3240 - Volume 13, número 31, 2020

questionou sobre os desenhos presentes na rocha e o motivo pelo qual esse mineral é especial. A rocha continha pinturas que representavam os hábitos de homens pré-históricos, como podemos ver a seguir na imagem 3:

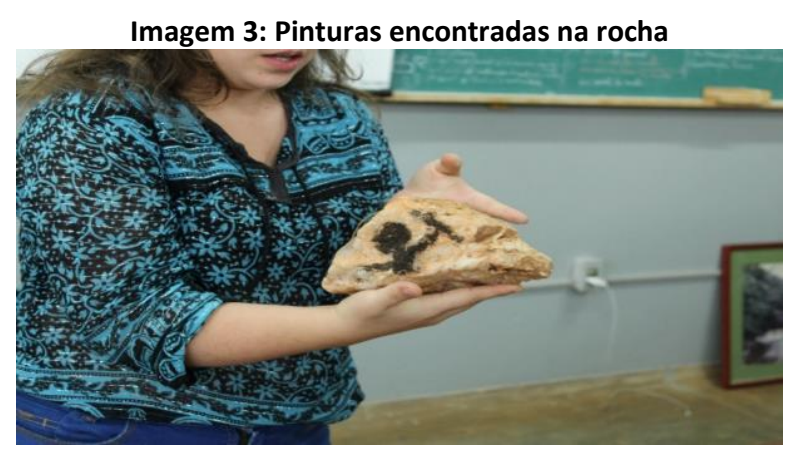

Fonte: AUTORES, 2018

No segundo momento da aula, os alunos foram instigados a desenharem, com tintas especiais, da mesma maneira que os homens pré-históricos trabalhavam com as pinturas a muitos anos atrás. Nesse momento, explicou-se o processo de fabricação da tinta por meio de minerais, através dos resíduos de traços de minerais diferentes, onde o pó foi misturado a clara de ovo, emulsificante, e água para proporcionar fluidez para pintar. Vejamos os resultados finais da atividade de desenho (IMAGEM 4 e 5):

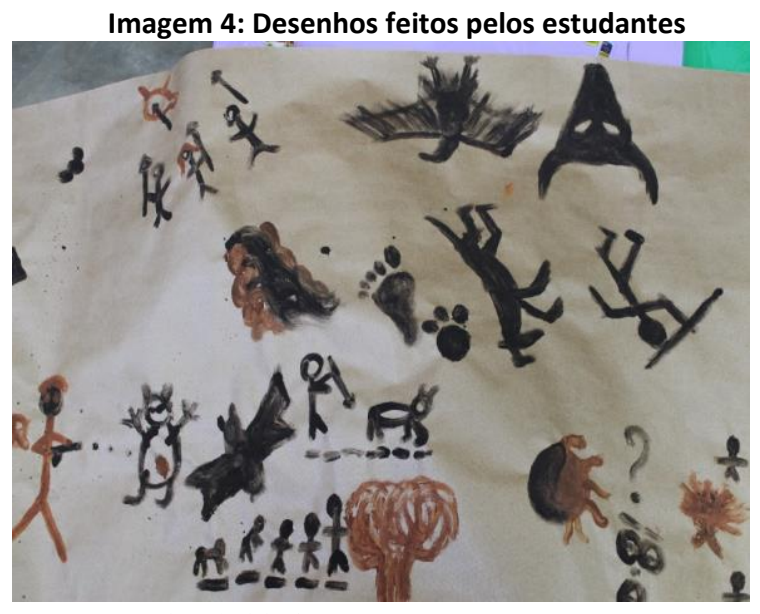

Fonte: AUTORES, 2018
Imagem 5: Desenhos feitos pelos estudantes

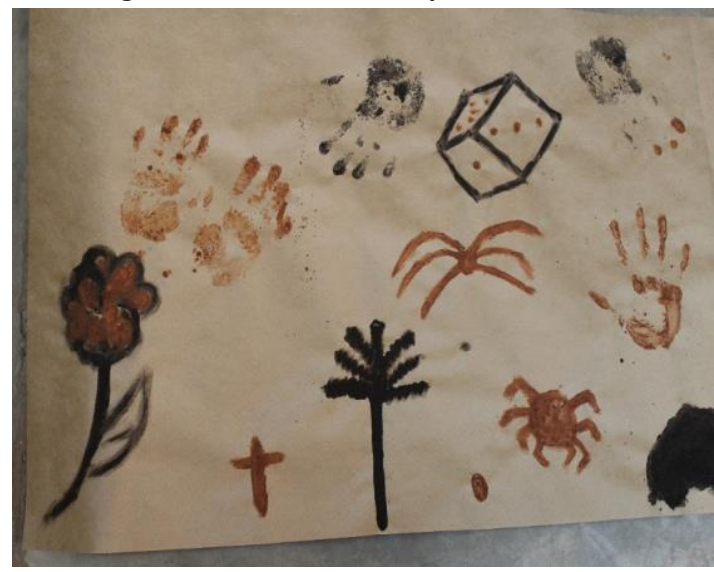

Fonte: AUTORES, 2018

A partir das diferenças de cores e citação dos elementos contidos em cada tinta, a professora questionou a característica que proporcionam tal propriedade de cor. As perguntas também foram no sentido de nortear aos discentes o conceito de elementos químicos, a partir problematização, "dividindo os minerais em que micropartículas conseguiríamos chegar?", permeou-se o conceito de átomo e ligações químicas que proporcionam a interação dos elementos, assim chegando-se ao conceito de composto.

Para avaliar os conhecimentos adquiridos na aula, utilizou-se a música "Ouro Escravo" de Jair dos Santos e Normi de Freitas, música vista como meio para indicar a importância de um mineral considerado precioso pela história do Brasil.

A avaliação teve como eixo o requisito uma paródia de uma música qualquer do cotidiano dos 
alunos em que os alunos deveriam produzi-la com os saberes da aula. A seguir, estão dois exemplos de paródias apresentadas pelos alunos da disciplina. Os estudantes foram identificados com a letra E seguido de um número para manter sua identidade em sigilo.

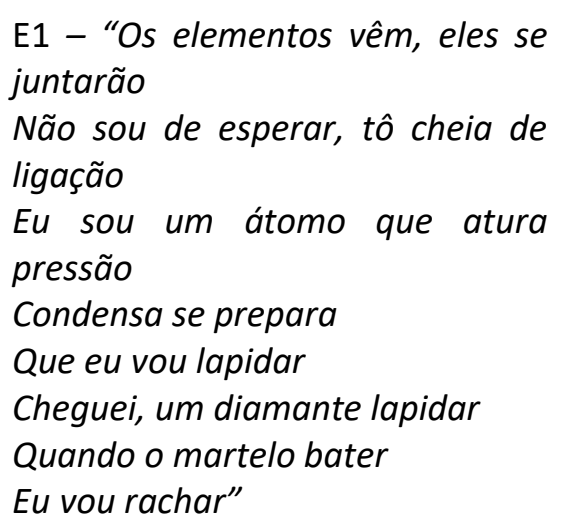

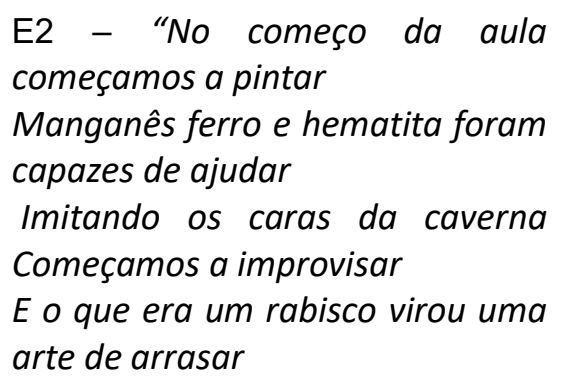

\section{METODOLOGIA}

Ao final da aula, foi pedido aos discentes que respondessem, de forma escrita, a seguinte pergunta: "Quais os pontos positivos e os pontos a serem melhorados da prática desenvolvida?". Para analisar as falas dos participantes, foi utilizada a análise de categoria, método de análise dos dados de uma pesquisa qualitativa (MORAES, 1999). Com a categorização, o pesquisador pode compreender a relevância da atividade como um todo, entendendo como as avaliações dos participantes se relacionam e quais aspectos elas apresentam em comum. De acordo com Gomes (2002), as categorias são criadas para se estabelecer um sistema de classificação e refletir sobre determinados aspectos da pesquisa em questão.

\section{RESULTADOS E DISCUSSÃO}

O quadro a seguir mostra as categorias encontradas, sua descrição e frequência. Os estudantes foram identificados com a letra A seguida de um número.

Quadro 1: Categorias, descrição e frequência

\begin{tabular}{|l|c|c|}
\hline \multicolumn{1}{|c|}{ Categorias } & Descrição & Frequência \\
\hline Recursos pedagógicos & $\begin{array}{c}\text { Nesta categoria reúnem-se as falas que citam os } \\
\text { recursos pedagógicos como meios importantes } \\
\text { para chamar atenção dos estudantes durante a } \\
\text { aula. }\end{array}$ & $\begin{array}{c}\text { A1, A2, A3, A4, A5, A7, A8, } \\
\text { A9, A11, A12, A13, A16, } \\
\text { A17, A18, A19, A20, A21, } \\
\text { A22, A23. }\end{array}$ \\
\hline $\begin{array}{l}\text { Desenho como forma de } \\
\text { incentivar a criatividade }\end{array}$ & $\begin{array}{c}\text { Estão agrupadas nesta categoria as falas que se } \\
\text { remetem ao desenho como uma ótima } \\
\text { ferramenta para estimular a criatividade dos } \\
\text { estudantes. }\end{array}$ & $\begin{array}{c}\text { A4, A5, A6, A7, A9, A12, } \\
\text { A13, A15, A21. }\end{array}$ \\
\hline $\begin{array}{l}\text { Domínio do conteúdo por } \\
\text { parte da professora }\end{array}$ & $\begin{array}{c}\text { Aqui estão reunidas as falas que apontaram o } \\
\text { domínio do conteúdo como característica para a } \\
\text { construção do conhecimento. }\end{array}$ & $\begin{array}{c}\text { A1, A2, A4, A5, A9, A18, } \\
\text { A21, A22. }\end{array}$ \\
\hline
\end{tabular}

Fonte: AUTORES, 2020

Partindo da análise feita nas avaliações dos estudantes que assistiram a prática pedagógica, foi 


\section{Revista Científica ANAP Brasil}

ISSN 1984-3240 - Volume 13, número 31, 2020

possível criar uma categoria denominada "Recursos pedagógicos", onde os estudantes apontaram a potencialidade dos recursos utilizados, como ilustra as falas a seguir:

A1 - "Foi muito interessante começar a aula com a caixa misteriosa, pois foi capaz de chamar atenção dos alunos(...)"

A2 - "Os recursos que a professora trouxe foram muito interessantes e didáticos. Incentivou a participação dos alunos o tempo todo."

A4 - "Boa música para trazer o tema de mineral e a importância histórica do Brasil."

A17 - "Aula super dinâmica, interação natural dos alunos por conta da curiosidade e atividade; A caixa aguçou nossa curiosidade e serviu muito bem para chamar os alunos para a aula."

A21 - "(...) Os recursos pedagógicos foram bem empregados e auxiliaram na construção dos conhecimentos à cerca dos minerais (...)"

A utilização de um recurso didático segundo Castoldi (2009) busca sanar algumas das problemáticas encontradas no ensino tradicional. Mas também, para o autor uma estratégia cumpre o papel de motivação e instigação do aluno para o aprendizado. Assim sendo, o recurso didático é um agente facilitador do processo de aprendizado do estudante. Para alunos que estão acostumados ao ensino tradicional, em que as metodologias são pouco variáveis e normalmente entendem o professor como centro do processo de ensino-aprendizagem, utilizar recursos inovadores torna possível instiga-los e faze-los sentir prazer por estarem na sala de aula.

Diante disso, um dos recursos utilizados durante a aula foi a música "Ouro Escravo" (1968) e, um dos pontos importantes de ser ressaltado é o fato de a música não pertencer a Indústria Cultural, conceito esse criado por Adorno e Horkheimer (1985) como sendo: o processo de industrialização que organiza a produção artística e cultural no contexto das relações capitalistas de produção, que são lançadas no mercado, vendidas e consumidas como qualquer outra mercadoria. Isso é possível de afirmar já que, de acordo com subtil (2007) não há um nivelamento uma padronização e um ajuste que a adeque na realidade das crianças e adolescentes atuais. Indo de encontro a isso, ao trabalhar com música dentro da sala de aula, deve-se ter um olhar cuidadoso no que diz respeito a indústria cultural, pois esta consegue difundir a ideologia capitalista, fortalecendo a manutenção de um sistema opressor.

Indo de encontro com essa preocupação, a música se faz muito importante dentro da sala de aula, pois, além de tornar possível o contato do estudante com esse tipo de arte, ela engloba questões histórico-culturais, políticas, econômicas e sociais. Em virtude disso, os autores Araújo; Paz (2011, p. 213) apontam que a "questão da funcionalidade da música também pode ser recolocada através das discussões sobre o projeto de individualismo burguês", podendo assumir um papel político ao denunciar a realidade e se prestando a um papel social de possibilitar a construção da criticidade dos estudantes.

Outro recurso utilizado em aula, foi a "caixa misteriosa" essa foi importante para iniciar a aula, pois permitiu que os estudantes se sentissem instigados a participar e descobrir o que havia dentro dela. Dessa forma, o processo de ensino-aprendizagem foi diferente do que comumente acontece, onde o professor é considerado detentor do conhecimento e os estudantes são apenas caixas vazias a serem preenchidas (FREIRE, 2014). Ao destacarem essa questão nas avaliações, os estudantes nos mostram que, um simples objeto criado no intuito de tornar a aula 


\section{Revista Científica ANAP Brasil}

ISSN 1984-3240 - Volume 13, número 31, 2020

mais dinâmica funciona e pode sim ser uma alternativa ao ensino tradicional.

O professor, ao se apropriar das possibilidades que os diferentes recursos pedagógicos apresentam, passam a ter a oportunidade de desenvolver aulas que despertem nos estudantes o interesse e a vontade de estar dentro da sala de aula para aprender. De acordo com Souza; Valin; Nascimento Junior (2018) os recursos pedagógicos podem funcionar como importantes ferramentas de auxilio nas salas de aula, contribuindo para enxergar um mundo cheio de novas experiências e dando "asas à imaginação".

Ainda se tratando dos recursos utilizados, os estudantes, ao avaliarem a aula, apontaram especificamente sobre o momento da aula que foi destinado aos desenhos, relacionados a pintura rupestre, apontando que isso tornou possível aguçar a criatividade dos alunos, como ilustram as falas quem compõe a segunda categoria "Desenho como forma de incentivar a criatividade".

A4 - "Ótima ideia de deixar os alunos desenharem com a mistura (...)."

A5 - "Boa escolha da metodologia, o desenho estimula a criatividade(...)."

A6 - "A atividade de realizar desenhos foi muito interessante para entendermos mais sobre pinturas rupestres e a cor promovida pelos minerais utilizados, além de despertar a criatividade dos alunos."

A7 - "Trazer tinta de terra para que pudéssemos manusear e desenhar foi o ponto máximo da aula. Um recurso que cativou os alunos; $A$ utilização disso para introduzir os conceitos facilitou o entendimento (...)."

Assim, se tratando de despertar a criatividade, Menezes e Guerra (2009, p. 12) apontam que "Imaginação, criatividade não são privilégios das Artes, aparecendo, também, na construção do conhecimento científico". Isso vai de encontro com o que aconteceu na prática, onde o ato de desenhar tornou possível a construção dos conceitos que estão por trás da tinta que utilizaram para pintar, de forma que facilitou a compreensão destes já que, a explicação do conceito passou a ser algo tangível para os estudantes.

Além de estimular a criatividade, durante o momento destinado ao desenho, os estudantes puderam conversar e interagir, visto que todos desenharam em um mesmo papel e utilizando as mesmas tintas. Essa interação é um evento extremamente importante para a valorização dos sujeitos e construção do conhecimento, pois nas palavras de Moreira (1995, p. 57) "enfatiza [...] a força e o papel do meio do conhecimento e da cultura na formação de características essencialmente humanas, o que se dá através de mediadores sociais".

Para que a construção do conhecimento se dê de forma efetiva, além do professor ter a preocupação de trazer recursos didáticos e trazer o aluno para mais próximo do processo de ensino-aprendizagem, é necessário que este domine o conteúdo a ser ministrado. Isso foi o que os estudantes apontaram na terceira categoria como um ponto positivo, já que, a partir disso, a aula se tornou mais prazerosa e se tornou mais fácil de aprender devido ao fato de a professora saber sobre o que está ministrando, como mostram as falas abaixo: 
A1 - "A professora demonstrou domínio do conteúdo e soube problematizar para construir $o$ conceito."

A18 - "Bom esclarecimento do tema devido ao domínio do conteúdo que a professora teve. Isso facilitou na compreensão."

A21 - "Bom domínio do conteúdo por parte da professora, o que facilitou o entendimento do conteúdo"

Nessa perspectiva, para Cunha; Krasilchik (2000) a formação atual de professores tem muitas problemáticas que ocorrem no despreparo para lidar com os conteúdos, principalmente nas áreas de Ciências, outrossim as autoras ainda refletem que para transformar os métodos de ensino é necessário do domínio teórico-pedagógico. Em especial os conceitos científicos estão sempre sendo revisados e modificados trazendo mudanças recorrentes na formação escolar básica, desse modo é necessário que os professores estejam sempre atualizados e em formação continuada, pois ao entender os conceitos com propriedade o professor tem domínio sobre a forma como ensinar, desse modo podendo trazer metodologias diferenciadas que se preocupam para além do conteúdo, aspectos também importantes que os estudantes precisam, como por exemplo a música e pintura de tintas naturais.

Dessa forma, a prática de ensinar exige que os professores estejam preparados de forma a dominar o conteúdo e, junto a isso, ter conhecimento de estratégias e uma visão crítica da realidade e da educação, para conseguir mediar o conhecimento com os estudantes, visando sua formação emancipatória. Para tal, é necessário que a aula apresente uma linguagem clara que estimule a curiosidade do aluno pelo conhecimento a ser ensinado (KAERCHER, 2012). Portanto, de acordo com Silva; Monteiro; Nascimento Júnior (2019), quando o professor domina o arcabouço teórico-prático que estrutura sua prática, o qual envolve, dentre outros, saberes científicos e pedagógicos, ele vai ao encontro de uma prática que pode ser capaz de fazer com que os estudantes se apropriem dos conteúdos de forma efetiva e, assim, se tornem sujeitos aptos a transformar a realidade na qual estão inseridos.

\section{CONSIDERAÇÕES FINAIS}

Diante do exposto, pode-se considerar a relevância de criar metodologias alternativas de ensino para o ensino de conceitos científicos, uma vez que isso, aliado a uma mediação crítica, possibilitará aos estudantes a apropriação dos conceitos que regem a natureza e, assim, serão capazes de se posicionar frente a situações que podem surgir em seu dia-a-dia.

Pode-se considerar também a potencialidade dos recursos pedagógicos utilizados, sendo eles a música e a caixa misteriosa, pois foram capazes de despertar a curiosidade dos estudantes e, por isso, instiga-los a participar da aula, fugindo, portanto, do método tradicional de ensino.

Ainda se tratando dos recursos pedagógicos, é possível afirmar a importância de levar a sala de aula atividades que incluam diferentes expressões artísticas e que estimule os estudantes a colocarem elas em prática, pois isso colabora para o desenvolvimento da criatividade dos alunos, fazendo com que se expressem e participem da aula. Aliado a isso, fazer esse tipo de atividade em conjunto, possibilita que haja interação dos alunos, rompendo uma lógica individualista dentro da sala de aula. 
Por fim, a partir da análise das falas, foi possível perceber a importância de o professor dominar o conteúdo dentro da sala de aula, pois é sabido que de nada adianta criar metodologias de ensino se o docente não estiver preparado para ministrar o conteúdo em si, distanciando-se de uma das funções da escola que é ensinar os conteúdos historicamente construídos e acumulados pelo homem para que assim o estudante seja capaz de interpretar os fenômenos que ocorrem em suas práticas sociais de maneira embasada.

\section{AGRADECIMENTOS}

CAPES, FAPEMIG E UFLA

\section{REFERÊNCIAS BIBLIOGRÁFICAS}

ADORNO, Theodor Wiesengrund; HORKHEIMER, Max. Dialética do esclarecimento. Rio de Janeiro, 1985.

ARAÚJO, Samuel; PAZ, Gaspar. Música, linguagem e Política; repensando o papel de uma práxis sonora. Terceira Margem, v. 15, n. 25, p. 211-231, 2011.

BRASIL. Ministério da Educação. Secretaria de Educação Média e Tecnológica. Parâmetros curriculares nacionais: ensino fundamental. Brasília: MEC/SEMTEC, 1998.

CACHAPUZ, António et al. A necessária renovação do ensino das ciências. 2005.

CORREIA, Ivy. Minerais: Sua utilização na nossa vida diária. In:

http://www2.unigranrio.br/unidades_adm/pro_reitorias/propep/sinctec/almanaqueunigranrio2014/trabalhos/458. pdf. Acesso em 17 de maio de 2020. UNIGRANRIO, 2014

COSTA, César Augusto Soares da; LOUREIRO, Carlos Federico Bernardo. Interdisciplinaridade, materialismo histórico-dialético e paradigma da complexidade: articulações em torno da pesquisa em educação ambiental crítica. Pesquisa em Educação Ambiental (Online), v. 14, p. 32-47, 2019.

CUNHA, Ana Maria de Oliveira; KRASILCHIK, Myriam. A formação continuada de professores de Ciências: percepções a partir de uma experiência. In: 23a Reunião da Associação Nacional de Pós-Graduação e Pesquisa em Educação, 2000, Caxambú. Educação não é privilégio - Anais em CD-ROM, 2000.

FREIRE, Paulo. Pedagogia da esperança: um reencontro com a pedagogia do oprimido. Editora Paz e Terra, 2014.

GOMES, Romeu. A análise de dados em pesquisa qualitativa. In: Pesquisa social. Teoria, método e criatividade. V. 23, P, 67-80, 2002.

HAGY, Renato Donato; CARNEIRO, Celso Dal Ré; GONÇALVES, Pedro Wagner. Como alunos aprendem noções sobre rochas e minerais? In: VII ENPEC - Encontro Nacional de Pesquisa em Educação de Ciências,Vol. s/n, pp.221-232, Florianópolis, SC, Brasil, 2009

KAERCHER, Nestor André. A Geografia como Midas é um obstáculo e um dos desafios da nossa docência. In: MUNHOZ, Gislaine (Org.) et al. Geografia - Estudo e Ensino -conhecimentos escolares e caminhos metodológicos. São Paulo: Ed. Xamã, 2012, p. 57-71.

KONDER, Leandro Augusto Marques Coelho. Os marxistas e a arte: breve estudo histórico-crítico de algumas tendências da estética marxista. 2. Ed. São Paulo: Editora Expressão Popular, 2013.

LABURÚ, Carlos Eduardo.; GOUVEIA, Amândio Augusto; BARROS, Marcelo Alves. Estudo de circuitos elétricos por meio de Desenhos dos alunos: uma estratégia pedagógica para explicitar as dificuldades conceituais. Caderno Brasileiro de Ensino de Física (online), v. 26, p. 24-47, 2009. 


\section{Revista Científica ANAP Brasil}

ISSN 1984-3240 - Volume 13, número 31, 2020

MENEZES, Ana Maria Santos.; GUERRA, Andréia. Literatura na Física: Uma Possível Abordagem Para o Ensino de Ciências? In: VII ENPEC - Encontro Nacional de Pesquisa em Educação em Ciências, 2009, Florianópolis. VII ENPEC Encontro Nacional de Pesquisa em Educação em Ciências, 2009.

MONTEIRO, Julia Amorim; ROSA, Marllon Moreti Souza; PAULA, Augusto Antonio de; ROSSO, Karen Luz Burgoa; NASCIMENTO JÚNIOR, Antonio Fernandes. Uma abordagem histórico-filosófica da ciência para a construção dos conceitos de trabalho, energia e entalpia: um relato de experiência na formação inicial de professores. In: V Encontro Nacional de Ensino de Ciências da Saúde e do Ambiente, 2018, Niterói/RJ. Anais do V Encontro Nacional de Ensino de Ciências da Saúde e do Ambiente, 2018. v. 1. p. 1-10.

MORAES, Roque. Análise de conteúdo. Revista Educação, Porto Alegre, v. 22, n. 37, p. 7-32, 1999.

OLIVEIRA, Adriane Dall' Acqua de. et al. A Ciência cantada: um meio de popularização da ciência e um recurso de aprendizagem no processo educacional. In: I Seminário Nacional de Educação Profissional e Tecnológica, 2008, Belo Horizonte. CEFET-Mg, 2008. v. 1

PAULA, Augusto Antonio de; MONTEIRO, Julia Amorim; REZENDE, Carla Castelari; NASCIMENTO JUNIOR, Antonio Fernandes. Análise da disciplina de Metodologia do Ensino de Biologia da Universidade Federal de Lavras - MG na formação inicial de professores. In: IV Congresso Nacional de Formação de Professores - CNFP e do XIV Congresso Estadual Paulista sobre Formação de Educadores, 2018, Águas de Lindóia. Anais do Anais do IV Congresso Nacional de Formação de Professores - CNFP e do XIV Congresso Estadual Paulista sobre Formação de Educadores, 2018.

QUIRINO, Eberton Borodinas; COUTO, Scarlet Silva; GONÇALVES, Laise Vieira; NASCIMENTO JUNIOR, Antonio Fernandes. $O$ ensino dos conceitos de Bioma e Biodiversidade a partir do uso de RPG como recurso didático. FÓRUM AMBIENTAL DA ALTA PAULISTA, v. 14, p. 26-38, 2018.

SANTOS, Ademilson Francisco dos; VOLKMER, Susana. Recursos minerais do Paraná: Litologias associadas à distribuição Geográfica e importância econômica, 2009.

SILVA, Adailton Araujo da. Proposta de um jogo didático no ensino de geociências: o ciclo das rochas no ensino fundamental, 2016.

SILVA, Yara Romanelli Campos Gonçalves; MONTEIRO, Julia Amorim; NASCIMENTO JUNIOR, Antonio Fernandes. O meio ambiente nas aulas de ciência: construindo conceitos de química a partir dos minerais. REVISTA CIENTíFICA ANAP BRASIL, v. 12, p. 75-87, 2019.

SOUZA, Michelle Julia; VALLIN, Celso; SOUZA, Gustavo Costa de; NASCIMENTO JUNIOR, Antonio Fernandes. Educação ambiental e parcerias público-privadas: uma investigação no município de Lavras - MG. FóRUM AMBIENTAL DA ALTA PAULISTA, v. 15, p. 43-55, 2019

SOUZA, Michelle Julia de; VALLIN, Celso; NASCIMENTO JUNIOR, Antonio Fernandes. O desenvolvimento de estratégias pedagógicas para o ensino dos biomas brasileiros em atividades do estágio supervisionado da licenciatura em Biologia a partir de experiências do Programa Institucional de Bolsas de Iniciação a Docência. FÓRUM AMBIENTAL DA ALTA PAULISTA, v. 14, p. 96-109, 2018.

SUBTIL, Maria José. Arte/música e indústria cultural - relações e contradições. In: 30a Reunião Anual da ANPEd, 2007, Caxambu. 30a Reunião Anual da ANPEd - website (em outubro). Rio de Janeiro: Anped, 2007. p. 1-16

TARDIF, Maurice; LESSARD, Claude; LAHAYE, L. Os professores face ao saber - esboço de uma problemática do saber docente. Teoria \&amp; Educação, Porto Alegre, n. 4, 1991. 